\title{
Relationship between fat free mass index values and use of nutritional supplement as an ergogenic aid in bodybuilding
}

\author{
A. Devrim, B. Aslantaş and P. Bilgiç \\ Hacettepe University, Department of Nutrition and Dietetics, Ankara, Turkey
}

Recent studies have shown that bodybuilders who weight train and do not take any ergogenic aids cannot have fat free mass index (FFMI) scores of more than $25^{(1-6)}$. We aim to investigate the association between prevalence of FFMI values and use of nutritional supplement as an ergogenic aid among Turkish bodybuilders.

One hundred twenty male bodybuilders included in this study. Their height and weight were measured and FFMI score were calculated. Nutritional supplements use was self-reported by bodybuilders. Data were analyzed using the IBM SPSS Statistics $23 \cdot 0$. Descriptive analyses were used to determine FFMI values of bodybuilders.

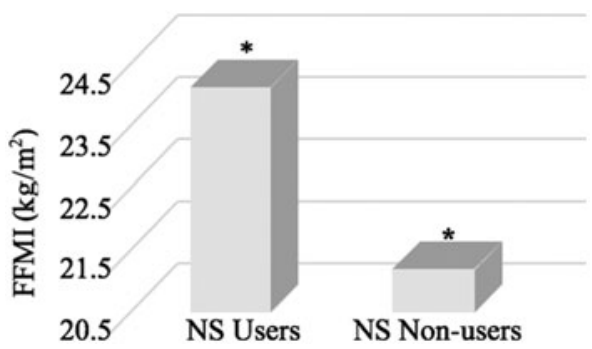

Fig. 1. FFMI values of nutitional supplement users and non-users $\left({ }^{*} \mathrm{p}<0.05\right.$.

In this study, the mean FFMI values of the nutritional supplements users and non-users were $24.09 \pm 3.05 \mathrm{~kg} / \mathrm{m} 2 \mathrm{and} 21.18 \pm 1.93$ $\mathrm{kg} / \mathrm{m} 2$. Compared the values of FFMI, the FFMI values of the nutritional supplements users were significantly higher than non-users $(\mathrm{p}<0.001)$. According to the results, protein powder, especially whey protein, brain- chained amino acid (BCAA), creatine and multivitamins were the most commonly used nutritional supplements in participants (respectively; \% $\% 77 \cdot 5, \% 54 \cdot 6, \% 47 \cdot 9$ and $\% 43 \cdot 3$ ). The reasons given most commonly by the bodybuilders for nutritional supplement use was to grow muscles $(\% 76 \cdot 1)$.

Consequently, there are significantly important differences in FFMI values for nutritional supplement users and non-users. With the data obtained from the study, muscle growth was the most frequently targets. For this reason, they tend to use nutritional supplements and consequently their FFMI values were increased according to non-users.

1. Goldfield GS \& Woodside DB (2009) Phys Sportsmed 37, 111-114.

2. Kanayama G, Hudson JI \& Pope HG (2008) Drug and alcohol dependence 98, 1-12.

3. Kanayama G, Hudson JI \& Pope HG (2010) Horm Behav 58, 111-121.

4. Keane H (2005) Health (London) 9: 189-208.

5. Pope HG, Kanayama G, \& Hudson JI (2012) Biological Psychiatry 71, 254-261.

6. Rohman L (2009) Eat Disord 17, 187-199. 